\title{
Strategi meningkatkan kualitas pendidikan di sekolah
}

Oleh:

Dwi Ayu Pradina

Email: dienaelnajma29@gmail.com

\begin{abstract}
ABSTRAK
Banyak cara dan usaha yang dilakukan oleh pemerintah untuk menunjang dan menin gkatkan kualitas pendidikan sekolah, seperti menerbitkan peraturan pemerintah RI Nomer 19 tahun 2005 tentang standar nasional pendidikan. ${ }^{1}$ Saya akan mengupas sedikit tentang sekolah MTS X merupakan salah satu lembaga pendidikan formal swasta dihadapkan deng an masalah bagaimana meningkatkan kualitasnya. Penelitian yang dilakukan bertujuan untuk mengidentifikasi peluang, ancaman, kekuatan dan kelemahan, untuk perencanaan strategis yang tepat untuk meningkatkan kualitas. Penelitian ini menggunakan metode kualitatif . menurut laporan yang diperoleh dari pihak-pihak yang mengetahui kondisi dan keadaan sekolah tersebut. Hasil dari penelitian ada beberapa hal yang harus dihadapi yaitu ada peluang, ancaman, kekuatan dan kelemahan yang berasal dari sekolah MTS X. Hal inilah yang menjadi faktor utama untuk meningkatkan kualitasnya. Hasil dari identifikasi situasi dan kondisi itu dibentuklah beberapa strategi yang dapat digunakan untuk meningk atkan kualitasnya. Ada beberapa strategi yang lebih difokuskan yang dapat digunakan untu k meningkatkan dan menunjang sekolah MTS X ini yaitu pada peningkatan kualitas melal ui pembelajaran, pemenuhan infrastruktur, penambahan tenaga kerja pendidik, mencari jaringan diluar dengan cara bekerja sama antara satu dengan yang lainnya.

Kata kunci : peluang, Ancaman, kekuatan, kelemahan, strategi, kualitas lembagalembaga dengan jalur pendidikan formal memegang peranan penting untuk pengembangan sumber daya manusia maka dari itu butuh yang namanya keseimbangan antar satu dengan yang lain.
\end{abstract}

\section{PENDAHULUAN}

\section{A. PENDAHULUAN}

\footnotetext{
${ }^{1}$ Jsh jurnal sosial humairo, vol 5 no.2,november 2012206
} 
Lembaga pendidikan formal masih menjadi pegangan dalam perkembangan sumber daya manusia diindonesia mengingat kembali jalur pendidikan formal masih menjadi andalan dalam mendidik masyarakat. Baik pada tingkat dasar, menengah maupun tinggi, lembaga pendidikan formal senantiasa diandalkan untuk menjadikan anak bangsa Indonesia semakin berkualitas dan dapat dihandalkan. Pentingnya peranan lembaga formal dalam dunia pendidikan di Indonesia 42 lembaga-lembaga formal menuntut harus memiliki kualitas yang baik agar output yang dihasilkan oleh lembaga ini juga berkualitas dan sesuai dengan standars nasional. Hal tersebut menjad i upaya bagi pendidik dan tenaga didik yang ada di dalam lembaga tersebut untuk men gembangkan visi, misi, dan tujuan yang menjadi sasaran pertama dalam pelaksanaan proses pendidikan yang ada disana. Dimana sasaran tersebut dapat diperoleh dari penelitian yang tentunya telah dilakukan oleh pihak yang memiliki tanggung jawab dalam hal tersebut. Kebijakan yang dilakukan oleh pemerintah tentunya merupakan hal yang harus dilaksanakan bagi sekolah dalam pencapaian strategi sekolah yang bermutu. Dalam kebijakan tersebut kemudian harus bisa diyakinkan bawah hasil akhir dapat meminalisir sekolah tersebut dengan berbagai mutu pelayanan yang layak. Tida $\mathrm{k}$ hanya sekolah swasta yang menjadi tunjangan dalam keberhasilan pembelajaran, fas ilitas yang ada baik dari sarana dan prasarana dalam sekolah juga mendukung keberha silan dalam proses pembelajaran.

\section{B. Faktor Utama Meningkatkan Kualitas Pendidikan Sekolah}

Untuk meningkatkan kualitas pendidikan disekolah, sudarwan danim,(2007:56) mengatakan bahwa jika sebuah institusi kualitas pendidikannya maka hendak meningkatkan pendidikannya maka minimal harus melibatkan 5 faktor yang dominan, yaitu

\section{Kepemimpinan / kepala sekolah}

Kepala sekolah harus dan wajib memiliki visi dan misi serta memahami da n mengaplikasikannya,memahami komponen-komponen kurikulum disekolah, bisa mengantarkan sekolah yang lebih baik dari sebelumnya, memberikan cont oh dalam berdisiplin serta menegakkan kedisiplinan dalam aktivitasnya.

Seorang kepala sekolah juga harus bisa melakukan perubahan yang lebih positif dalam mengupayakan sekolahyang dipimpinnya.

2. Guru 
Pelibatan guru secara maksimal, karena guru adalah pendidik dan merupakan jantug sekolah dengan tugas utamanya mendidik, mengajar, me mbimbing, melatih, menilai dan mengevaluasi peserta didik. ${ }^{2}$

Guru adalah pendidik yang menjadi cerminan dan indentifikasi bagi peserta didik dan lingkungannya. Sebab itu seorang guru wajib memiliki sifat dan kepribdian yang baik dan berkualitas untuk mencakup tanggung $\mathrm{j}$ awab,wibawa,mandiri dan disiplin. ${ }^{3}$

Pihak sekolah juga harus bisa meningkatkan kompetensi dan profesi ke rja guru dalam kegiatan seminar lokalkarya serta pelatihan sehingga hasil dari kegiatan tersebut dapat diterapkan disekolah untuk menambah wawas an peserta didik untuk menghindari rasa suntuk yang dialami hal ini kerapt terjadi kepada sebagian peserta didik.

3. Peserta didik

Untuk mencapai keberhasilan dalam proses belajar mengajar peran gur u sebagai tenaga pendidik dan peserta didik sebagai subjek pembelajaran sangat berpengaruh. Kurangnya keterampilan guru dalam melaksanakan tu gasnya sebagai pendidik bisa menyebabkan faktor ketidak seimbangan did alamnya. Adapun cara-cara untuk memberikan pemahaman kepada peserta didik yaitu dengan Pendekatan yang harus dilakukan adalah " anak sebagai pusat " sehingga kompetensi dan kemampuan siswa dapat digali sehigga sekolah dapat menginvertasirir kelebihan yang ada pada siswa.

4. Kurikulum

Menurut pendapat Hilda Taba, Kurikulum adalah sebuah rancangan pembelajaran serta perkembangan individu. Ada beberapa pendapat lain mengenai kurikulum, kurikulum merupakan keseluruhan pengalaman yang ditawarkan pada anak-anak peserta didik dibawah arahan dan bimbingan sekolah. Pendapat ini dikemukakan oleh Ronald C.D

Dengan Adanya kurikulum yang konsisten, dinamis dan terpadu dapat memungkinkan dan memudahkan standar kualitas yang diharapkan sehing ga tujuan dapat dicapai secara maksimal.

\footnotetext{
${ }^{2}$ Anas salahuddin, filsafat pendidikan ( Bandung: penerbit setia pustaka, 2011),219

${ }^{3}$ E.mulyasa, Menjadi Guru Professional, ( Bandung: penerbit PT Remaja Rosdakarya,2008),37.
} 
5. Jaringan kerja sama

Jaringan kerjasama tidak hanya terbatas pada lingkungan sekolah dan masyarkat semata ( orangtua dan masyarakat) tetapi dengan organisasi lain seperti perusahaan atau instansi pemerintahan sehingga output dari sekola $\mathrm{h}$ dapat terserap didalam dunia kerja.

Berdasarkan pendapat diatas dapat dijelaskan bahwa kepala sekolah, guru peserta didik, masyarakat dan jaringan organisasi mempuyai tanggun g jawab besar terhadap peningkatan kualitas pendidikan disekolah. Utama nya guru, karena guru karena guru sebagai ujung tombak dikelas yang bers entuhan langsung dengan siswa dalam proses pmbelajaran. Oleh karena itu untuk meningkatkan mutu pembelajaran, seorang guru harus mempunyai syarat yang diperlukan dalam mengajar dan membangun pembelajaran sis wa secara efektif dikelas.

\section{PENINGKATKAN KUALITAS PENDIDIKAN MELALUI PEMBELAJARAN}

Syaiful Sagala (2003: 63), menyatakan bahwa pembelajaran mempunyai dua $\mathrm{k}$ arakteristik. Pertama, dalam proses pembelajaran melibatkan proses berfikir. Kedu a, dalam proses pembelajaran membangun suasana dialogis dan tanya jawab terus menerus yang diarahkan untuk memperbaiki dan meningkatkan kemampuan berfik ir siswa, yang pada gilirannya kemampuan berfikir itu dapat membantu siswa untu k memperoleh pengetahuan yang mereka konstruksi sendiri. Dari uraian diatas,dap at difahami bahwa proses pembelajaran yang baik dapat dilakukan oleh siswa baik di dalam maupun diluar kelas, dan dengan karakteristik yang dimiliki oleh siswa di harapkan mereka mampu berinteraksi dan bersosialisasi dengan teman temannya se cara baik dan bijak. Dengan intensitas yang tinggi serta belajar secara berkesinamb ungan diharapkanproses interaksi sosial sesama teman dapat tercipta dengan baik d an pada gilirannya mereka saling menghargai dan menghormati satu sama lain wal aupun dalam perjalanannya mereka saling berbeda pendapat yang pada akhirnya $\mathrm{m}$ ereka saling menumbuhkan sikap demokratis antar sesama. Paradigma metodologi pendidikan saat ini disadari atau tidak telah mengalami suatu pergeseran dari behav iourisme ke konstruktivisme.

Pendidikan adalah salah satu yang terencanauntuk mewujudkan cita-cita dengan melewati proses belajar mengajar dengan tujuan agar peserta didik secara 
langsung dan insiatif mengembangkan potensi yang dimilikinya dengan adanya pendidikan semua ynag dimiliki baik kelebihan IQ nya keterampilan dalam extrakulikulernya bisa di terapkan dan di aplikasikan sehingga apa yang dimilikinya tidak terasa sia sia dengan dimilikinya kecerdasan, akhlak mulia serta keterampilan bisa menjadikan benteng untuk masyarakat, bangsadan negara ${ }^{4}$. untuk mencerdaskan dan mengembangkan efektif dan moral murid berdirilah sekolah, Sebab itu banyak masyarakat memiliki harapan besar terhadap sekolah sekolah agar dapat membantu pembentukan pengetahuan serta moral seorang pelajar menuju kematangan kecerdasan, emosional, serta spiritual.

Hal ini menjadi bentuk antusiasme kepala sekolah untuk mengevaluasi visi, misi, kurikulum, kinerja guru, serta staf sekolah. Pada kumpulan dokumen mungkin tercatat bahwa pelaksanaan pembelajaran terlihat baik, namun dalam pelaksanaannya bisa jadi menyimpang dari dokumen yang ada, baik itu disebabkan oleh faktor internal ataupun eksternal, finansial maupun nonfinansial.

Seorang pendidik harus mengetahui kelima tipe di atas agar mudah mengetahui metode belajar yang tepat pada setiap peserta didik. Bila seorang pendidik telah memahami karakter setiap murid, maka ia tinggal melaksanakan usaha pencapaian tujuan pembelajaran sesuai dengan metode yang ia ketahui dan dipahami.

Menyampaikan materi pelajaran, keterampilan, atau sikap tertentu agar pembelaja ran dan pendidikan berlangsung efektif, dengan harapan tercapainya proses KBM dengan baik. Guru harus menguasai materi pengajaran dengan baik, sehingga ia mudah memilih metode yang tepat untuk mengajarkannya metode yang kerap dilakukan adalah metode mengajar dan mendekati peserta didik dengan ikatan emosional.

\section{METODE MENINGKATKAN KUALITAS PENDIDIKAN DISEKOLAH}

Ada 2 metode yaitu, pendekatan yang menjadi unsur penting dalam peningkatan $\mathrm{k}$ ualitas pembelajaran dan pendidikan di sekolah dalam sudut pandang mikro dan makr

${ }^{4}$. Dalam UU No. 20 Tahun 2003 tentang Sistem Pendidikan Nasional Bab 1 Pasal 1 Poin 1. Jejen Musfah. Manajemen Pendidikan Teori, Kebijakan, dan Praktik, Edisi Pertama, Jakarta: PRENADAMEDIA GROUP, 2015.,Hal 14 
o. Sebagaimana dijabarkan berikut ini:

1. Pendekatan Mikro

Pendidikan Yaitu suatu pendekatan terhadap pendidikan dengan indikator kajiannya dilihat dari hubungan antara peserta didik, pendidik, dan interaksi keduany dalam usaha pendidikan. Secara lengkap elemen mikro adalah: Kualitas manajemen, Pemberdayaan satuan pendidikan, Profesionalisme dan ketenagaan, Relevansi dan keb utuhan. Berdasarkan tinjauan mikro elemen guru dan siswa yang merupakan bagian d ari pemberdayaan satuan pendidikan merupakan elemen sentral. Pendidikan untuk ke pentingan peserta didik mempunyai tujuan, dan untuk mencapai tujuan ini ada berbag ai sumber dan kendala dengan memperhatikan sumber dan kendala ditetapkan bahan pengajaran dan diusahakan berlangsungnya proses untuk mencapai tujuan. ${ }^{5}$

2. Pendekatan Makro Pendidikan

Pendekatan makro pendidikan yaitu kajian pendidikan dengan elemen yang lebih luas, yaitu dengan elemen sebagai berikut: Standarisasi pengembangan kurikulu m, pemerataan, persamaan dan keadilan, standar mutu dan kemampuan bersaing. Seda ngkan pendekatan makro pendidikan menyangkut berbagai hal yaitu melalui jalur pert ama yaitu INPUT SUMBER PROSES PENDIDIKAN HASIL PENDIDIKAN (Etty Rochaety, 2005: 8). Selanjutnya Syaiful (2004: 9) menyatakan solusi manajemen pen didikan secara mikro dan makro Solusi manajemen pendidikan secara mikro dan makr o Secara umum untuk meningkatkan kualitas pendidikan harus diawali dengan strateg i peningkatan pemerataan pendidikan, di mana unsur makro dan mikro pendidikan iku t terlibat, untuk menciptakan Equality dan Equity, mengutip pendapat Indra Djati Sidi (2001: 73) bahwa pemerataan pendidikan harus mengambil langkah strategi sebagai b erikut:

1. Pemerintah menanggung biaya minimum pendidikan yang diperlukan anak usia sekolah baik negerimaupun swasta yang diberikan secara individual kepadasiswa.

${ }^{5}$ Ibid. Vol 5 No. 2, 
2. Optimalisasi sumber daya

Pendidikan yang sudah tersedia, antara lain melalui double shift (conto h pemberdayaan MTS X terbuka dan kelas jauh),

3. Memberdayakan sekolah-sekolah

Menjaga dan memberikan yang terbaik untuk sekolah- sekolah yang tertinggal dari pusat kota demi meningkatkan kualitas peserta didik yang ada didalamnya. Termasuk sekolah swasta dengan melalui bantuan dan subsidi dalam rangka peningkatan mutu pembelajaran siswa dan mengoptimalisasi daya yang tersedia.

\section{Meningkatkan partisipasi}

Anggota masyarakat dan pemerintahan daerah untuk ikut serta menanga ni penuntasan wajib belajar pendidikan dasar 9 tahun demi kemajuan anak ban gsa khususnya indonesia dan demi menghindari prahara pernikahan dini yang banyak terjadi dikalangan masyarakat umum dan awam, karena bagaimanapun ini juga berpangaruh kepada jumlah kematian ibu muda. Mari bersama-sama memberikan pendidikan yang terbaik untuk anak- anak bangsa.

\section{E. KESIMPULAN}

Sekolah berdiri dan didirikan untuk mencerdaskan serta mengembangkan keefektif an moral murid. Sebab itu,ada harapan besar bagi masyarakat terhadap sekolah - 
sekolah agar dapat membantu pembentukan pengetahuan serta moral seorang pelajar menuju kematangan kecerdasan, emosional, serta spiritual.

Seorang pendidik harus mengetahui kelima tipe di atas agar mudah mengetahui metode belajar yang tepat pada setiap peserta didik. Bila seorang pendidik telah memahami karakter setiap murid, maka ia tinggal melaksanakan usaha pencapaian tujuan pembelajaran sesuai dengan metode yang ia ketahui dan dipahami.

Berdasarkan penjelasan diatas bahwa, guru dan peserta didik, mempuyai tanggung jawab besar terhadap peningkatan kualitas pendidikan disekolah. Utamanya guru, kar ena guru karena guru sebagai ujung tombak dikelas yang bersentuhan langsung denga $\mathrm{n}$ siswa dalam proses pmbelajaran. Oleh karena itu untuk meningkatkan mutu pembel ajaran, seorang guru harus mempunyai syarat yang diperlukan dalam mengajar dan $\mathrm{m}$ embangun pembelajaran siswa secara efektif dikelas dan tentunya pelayanan juga dibe rikan untuk menambah fasilitas sekolah.

Pelayanan yang diberikan oleh lembaga tentunya telah sesuai dengan kebutuhan yang harus dipenuhi dan diberikan kepada tenanga pendidik dan peserta didik, dimana hal tersebut yang akan mendukung lancarnya proses pembelajaran sehingga dapat terhindar dari kendala-kendala yang akan ada. Diantaranya pelayanan yang ada meliput pelayanan dari internal(/lembaga/sekolah) yang menyediakan dan juga pelayanan dari eksternal (peserta didik dan masyarakat/wali murid) yang juga mendukung keberhasilannya.

Setelah pelayanan yang diberikan oleh sekolah dan juga faktor lain dari luar sekola $\mathrm{h}$ yang juga mengerakkan perkembangan layanan pendidikan akan menghasilkan hasil kinerja yang kemudian menjadi titik penilaian bagi lembaga itu sendiri dari mayaraka t tentang kepuasan atas hasil pendidikannya, dapat sesuai atau tidak kah dengan harapan mereka dan tentunya juga meliputi harapan/tujuan lembaga itu sendiri.

Termasuk pelayanan dari pemerintah yang juga dapat membantu meningkatkan kualitas pendidikan disekolah baik sekolah dikedalaman maupun diluar, yang tentuny a masih banyak sekali harapan mengenai pelayanan yang ada. 


\section{DAFTAR PUSTAKA}

http://dedinoviyanto.wordpress.cpm/my-papers/tentang-pendidikan/konsep-kepuasanpelanggan-dalam-manajemen-mutu-pendidikan-islam/. Diakses pada tanggal 31 APRIL 2018

Edward Sallis. 2006. Total Quality Management In Education (alih Bahasa Ahmad Ali Riyadi ). Jogjakarta : IRCiSoD

Eti Rochaety,dkk.2005 . Sistem Informamsi Manajemen Pendidikan. Jakarta: bumi Aksara Indra Djati Sidi.2003. Menuju Masyarakat Belajar. Jakarta : Logos

Muhibbin, Zainul. 2011. Problematika MTs Swasta di SurabayaMenghadapi Era Global, Laporan Penelitian, LPPM-ITS

Republik Indonesia. (2003). Undang-Undang Nomor 20 tahun 2003 Tentang Sistem Pendidikan Nasional. Jakarta: Kloang klede Putra Timur

Rahman, Arif. 2009, Materi Workshop Peningkatan Kompetensi Mengajar melalui Konse p Metaforming, Jakarta UNJ

Sagala, Syaiful.2004. Manajemen Berbasis Sekolah \&Masyarakat. Bandung : alfabeta

Sagala, Syaiful.2005.Administrasi Pendidikan Kontemporer. Bandung: jurnal manajemen Vol 5 No. 2. Diakses pada tanggal 1 APRIL 2018.

Baharun, Hasan.dkk. 2017. Pengembangan kurikulum. Yogyakarta: pustaka nurja,2017 